\title{
Does Brachial Plexus Blockade Result in Improved Pain Scores After Distal Radius Fracture Fixation? A Randomized Trial
}

\author{
David K. Galos MD, David P. Taormina MD, Alexander Crespo MD, \\ David Y. Ding MD, Anthony Sapienza MD, Sudheer Jain MD, \\ Nirmal C. Tejwani MD
}

Received: 23 October 2015/ Accepted: 2 February 2016/Published online: 11 February 2016

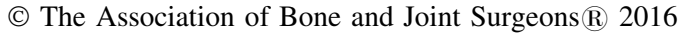

\begin{abstract}
Background Distal radius fractures are very common injuries and surgical treatment for them can be painful. Achieving early pain control may help improve patient satisfaction and improve functional outcomes. Little is known about which anesthesia technique (general anesthesia versus brachial plexus blockade) is most beneficial for pain control after distal radius fixation which could significantly affect patients' postoperative course and experience.

Questions/Purposes We asked: (1) Did patients receiving general anesthesia or brachial plexus blockade have worse pain scores at 2, 12, and 24 hours after surgery? (2) Was there a difference in operative suite time between patients who had general anesthesia or brachial plexus blockade,
\end{abstract}

Each author certifies that he or she, or a member of his or her immediate family, has no funding or commercial associations (eg, consultancies, stock ownership, equity interest, patent/licensing arrangements, etc) that might pose a conflict of interest in connection with the submitted article.

All ICMJE Conflict of Interest Forms for authors and Clinical Orthopaedics and Related Research ${ }^{\circledR}$ editors and board members are on file with the publication and can be viewed on request. Clinical Orthopaedics and Related Research ${ }^{\mathbb{B}}$ neither advocates nor endorses the use of any treatment, drug, or device. Readers are encouraged to always seek additional information, including FDAapproval status, of any drug or device prior to clinical use.

Each author certifies that his or her institution approved the human protocol for this investigation, that all investigations were conducted in conformity with ethical principles of research, and that informed consent for participation in the study was obtained.

D. K. Galos, D. P. Taormina, A. Crespo, D. Y. Ding, A. Sapienza, S. Jain, N. C. Tejwani $(\bowtie)$

NYU Hospital for Joint Diseases, Langone Medical Center,

301 East 17th Street, Suite 1402, New York, NY 10003, USA

e-mail: nirmal.tejwani@nyumc.org;

nirmal.tejwani@med.nyu.edu and was there a difference in recovery room time? (3) Did patients receiving general anesthesia or brachial plexus blockade have higher narcotic use after surgery? (4) Do patients receiving general anesthesia or brachial plexus blockade have higher functional assessment scores after distal radius fracture repair at 6 weeks and 12 weeks after surgery?

Methods A randomized controlled study was performed between February, 2013 and April, 2014 at a multicenter metropolitan tertiary-care referral center. Patients who presented with acute closed distal radius fractures (Orthopaedic Trauma Association 23A-C) were potentially eligible for inclusion. During the study period, 40 patients with closed, displaced, and unstable distal radius fractures were identified as meeting inclusion criteria and offered enrollment and randomization. Three patients (7.5\%), all with concomitant injuries, declined to participate at the time of randomization as did one additional patient (2.5\%) who chose not to participate, leaving a final sample of 36 participants. There were no dropouts after randomization, and analyses were performed according to an intention-totreat model. Patients were randomly assigned to one of two groups, general anesthesia or brachial plexus blockade, and among the 36 patients included, 18 were randomized to each group. Medications administered in the postanesthesia care unit were recorded. Patients were discharged receiving oxycodone and acetaminophen 5/325 $\mathrm{mg}$ for pain control, and VAS forms were provided. Patients were called at predetermined intervals postoperatively ( 2 hours, 4 hours, 6 hours, 12 hours, 24 hours, 48 hours, and 72 hours) to gather pain scores, using the VAS, and to document the doses of analgesics consumed. In addition, patients had regular followups at 2 weeks, 6 weeks, and 12 weeks. Pain scores were again recorded using the VAS at these visits. 
Results Patients who received general anesthesia had worse pain scores at 2 hours postoperatively (general anesthesia $6.7 \pm 2.3$ vs brachial plexus blockade $1.4 \pm 2.3$; mean difference, 5.381; 95\% CI, 3.850-6.913; $\mathrm{p}<0.001)$; whereas reported pain was worse for patients who received a brachial plexus blockade at 12 hours (general anesthesia $3.8 \pm 1.9$ vs brachial plexus blockade $6.3 \pm 2.4$; mean difference, $-2.535 ; 95 \% \mathrm{CI},-4.028$ to $-1.040 ; \mathrm{p}=0.002$ ) and 24 hours (general anesthesia $3.8 \pm 2.2$ vs brachial plexus blockade $5.3 \pm 2.5$; mean difference, $-1.492 ; 95 \%$ $\mathrm{CI},-3.105$ to $0.120 ; \mathrm{p}=0.031)$. There was no difference in operative suite time (general anesthesia $119 \pm 16$ minutes vs brachial plexus blockade $125 \pm 23$ minutes; $p=0.432$ ), but time in the recovery room was greater for patients who received general anesthesia (284 \pm 137 minutes vs $197 \pm$ $90 ; \mathrm{p}=0.0398$ ). Patients who received general anesthesia consumed more fentanyl $(64 \mu \mathrm{g} \pm 93 \mu \mathrm{g}$ vs $6.9 \mu \mathrm{g} \pm 14$ $\mu \mathrm{g} ; \mathrm{p}<0.001)$ and morphine $(2.9 \mu \mathrm{g} \pm 3.6 \mu \mathrm{g}$ vs $0.0 \mu \mathrm{g}$; $\mathrm{p}<0.001)$ than patients who received brachial plexus blockade. Functional outcome scores did not differ at 6 weeks (data, with mean and SD for both groups, and $\mathrm{p}$ value) or 12 weeks postoperatively (data, with mean and $\mathrm{SD}$ for both groups, and $\mathrm{p}$ value).

Conclusions Brachial plexus blockade pain control during the immediate perioperative period was not significantly different from that of general anesthesia in patients undergoing operative fixation of distal radius fractures. However, patients who received a brachial plexus blockade experienced an increase in pain between 12 to 24 hours after surgery. Acknowledging "rebound pain" after the use of regional anesthesia coupled with patient counseling regarding early narcotic administration may allow patients to have more effective postoperative pain control. It is important to have a conversation with patients preoperatively about what to expect regarding rebound pain, postoperative pain control, and to advise them about being aggressive with taking pain medication before the waning of regional anesthesia to keep one step ahead in their pain control management.

Level of Evidence Level 1, therapeutic study.

\section{Introduction}

Distal radius fracture fixation is one of the most commonly performed orthopaedic procedures but may be extremely painful for the patient, which can adversely affect patient outcomes and experience. General anesthesia and regional anesthesia are the current gold standards for intraoperative anesthesia. Regional anesthesia has a proven track record for success in upper and lower extremity surgery $[5,16]$. In the upper extremity it frequently involves brachial plexus blockade from various approaches (interscalene, supraclavicular, or infraclavicular). Strode [21] reported this method of anesthesia in 1929 for the treatment of fractures of the arm, and its use can be traced as far back as the late 1800s. Previous studies have shown excellent efficacy of the brachial plexus blockade $[4,14,16,19]$. The reported advantages of regional blockade include improved postoperative pain, decreased opioid use, and reduced recovery times compared with general anesthesia in upper extremity surgery [15, 17]. Regional anesthesia also provides excellent muscle relaxation, greater hemodynamic stability, reduced postanesthesia care unit (PACU) stay, decreased unplanned hospital admission for pain control, increased operating room efficacy, and greater patient satisfaction [3, 19, 22, 24]. Some authors have reported the efficacy of brachial plexus blockade in shoulder surgery and, to a lesser extent, in elbow surgery $[13,24]$.

To the best of our knowledge, only one study has focused on pain control after regional anesthesia for distal radius fracture treatment [8]. We know that rebound pain is an important factor after the operative treatment of other body parts when regional anesthesia is used, but we do not know how rebound pain affects patients undergoing distal radius fracture fixation while under regional anesthesia. Do these patients require more pain medications, more recovery room time, and/or have functional outcomes or patient satisfaction differences? In addition, we currently have little understanding regarding how to advise patients about optimal pain control after distal radius fracture fixation [1, 2, 9, 12]. We therefore decided to conduct a randomized study comparing pain control after distal radius fracture fixation in patients who received either general anesthesia or brachial plexus blockade to better understand this.

We asked: (1) Did patients receiving general anesthesia or brachial plexus blockade have worse pain scores at 2, 12, and 24 hours after surgery? (2) Was there a difference in operative suite time between patients who had general anesthesia or brachial plexus blockade, and was there a difference in recovery room time? (3) Did patients receiving general anesthesia or brachial plexus blockade have higher narcotic use after surgery? (4) Do patients receiving general anesthesia or brachial plexus blockade have higher functional assessment scores after distal radius fracture repair at 6 weeks and 12 weeks after surgery?

\section{Methods}

\section{Study Design and Setting}

A prospective, randomized controlled study was performed at a multicenter metropolitan tertiary-care referral center between February 2013 and April 2014 using patients who presented with acute closed distal radius fractures 
(Orthopaedic Trauma Association [OTA] Type 23A-C). All patients underwent open reduction and internal fixation with either brachial plexus blockade or general anesthesia (alone). Patients with open distal radius fractures, multiple injuries requiring other surgeries or pain medications, medical comorbidities precluding specific anesthesia types, or those refusing randomization were excluded.

\section{Participants/Study Subjects}

Patients were identified at the time of injury on presentation to the emergency department of our institution or during their preoperative consultation with a trauma or hand fellowship-trained orthopaedic surgeon. Inclusion criteria included a closed distal radius fracture (OTA Type 23A-C) indicated for operative fixation in patients older than 18 years. Operative indications include displaced, unstable distal radius fracture, with or without intraarticular involvement, in patients healthy enough to undergo surgery. Preoperatively, patients were recruited by research staff, who also obtained consent from the patients. The patients then were randomized to receive either general anesthesia or brachial plexus blockade.

\section{Demographics, Description of Study Population}

Between February 2013 and April 2014, 40 patients with closed, displaced, and unstable distal radius fractures were identified as meeting inclusion criteria and offered enrollment and randomization. Three patients $(7.5 \%)$, all with concomitant injuries, declined to participate at the time of randomization as did one additional patient $(2.5 \%)$ who did not want to participate, leaving a final sample of 36 patient participants. There were no dropouts after randomization. Patients were randomly assigned to one of two groups, general anesthesia or brachial plexus blockade and among the 36 patients included, 18 were randomized to each group. All patients in the brachial plexus blockade group tolerated the blocks as none received general anesthesia in addition to the block. There were no differences between groups regarding general demographics or injury characteristics (Table 1).

\section{Randomization}

Patients were randomized by research staff to either general anesthesia or single-shot infraclavicular brachial plexus blockade using a computerized random number generator, and the results were recorded and stored in opaque envelopes. The anesthesiologist and research staff
Table 1. Demographics and injury characteristics

\begin{tabular}{llll}
\hline Demographic & $\begin{array}{l}\text { General } \\
\text { anesthesia }\end{array}$ & $\begin{array}{l}\text { Brachial plexus } \\
\text { blockade }\end{array}$ & $\begin{array}{l}\mathrm{p} \\
\text { value }\end{array}$ \\
\hline $\begin{array}{l}\text { Age, years } \\
\text { (mean, [SD]) }\end{array}$ & $54.9[16.7]$ & $54.4[14.8]$ & 0.923 \\
$\begin{array}{l}\text { Sex } \\
\text { Male }\end{array}$ & & \\
Female & 6 & 9 & 0.316 \\
OTA fracture classification & 9 & \\
A & 7 & & 0.288 \\
B & 1 & 2 & \\
C & 9 & 1 & \\
\hline
\end{tabular}

OTA $=$ Orthopaedic Trauma Association

were not blind to randomization status. Given the nature of the study, patients may have been mildly sedated at the time of induction (versus brachial plexus blockade), but they were not explicitly blinded nor was a placebo used. Staff and researchers calling for followup reports were not explicitly blinded to the type of anesthesia that patients had received.

\section{Description of Experiment, Treatment, or Surgery}

Patients in the brachial plexus blockade group received only regional anesthesia and sedation without general anesthesia. The general anesthesia group received no additional local anesthesia. For the brachial plexus blockade group, an ultrasound-guided infraclavicular brachial plexus block was performed in a sterile fashion using a 22gauge Stimuplex ${ }^{\circledR}$ (B Braun Medical Inc, Bethlehem, PA, USA) block needle on entering the operating room. Twenty milliliters of $2 \%$ lidocaine with 1:200,000 epinephrine plus $15 \mathrm{cc}$ of $0.25 \%$ bupivacaine were injected after confirming negative aspiration every $5 \mathrm{cc}$ to $7 \mathrm{cc}$. For the general anesthesia group, the regimen was left to the discretion of the anesthesiologist based on the patient's medical profile. Some patients were managed with laryngeal mask airway, while others had endotracheal intubation with anesthetic maintenance guided by the patient's physiology. Fentanyl, a relatively short-acting opiate, was the only intraoperative analgesic given. No other opiate or nonopiate analgesics were administered intraoperatively. Just before incision, the surgeon assessed the quality of the regional anesthetic by providing a noxious stimulus with a pair of forceps to ensure adequate analgesia. All patients underwent open reduction with internal fixation by trauma or hand fellowship-trained orthopaedic surgeons (NCT, AS). All distal radius fractures were fixed with volar locked plates using a standard volar Henry approach. 


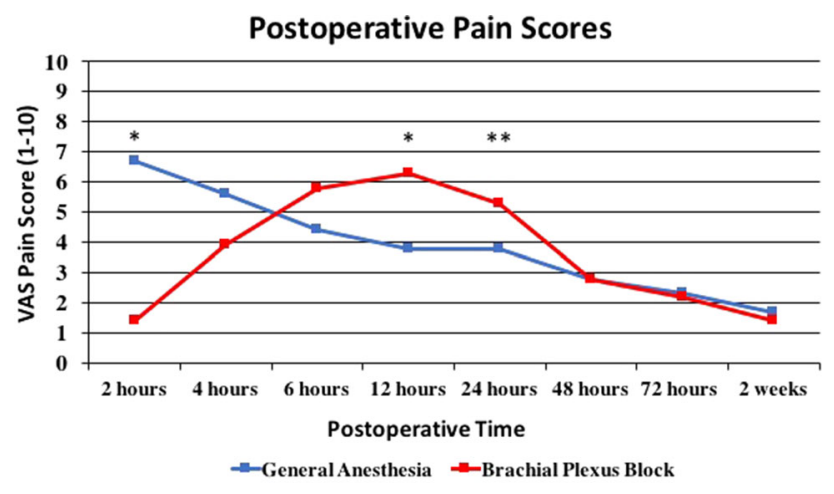

Fig. 1 Mean VAS pain scores (range, 0-10) through the postoperative period are shown. Differences between groups were seen at 2 hours $(\mathrm{p}<0.001), 12$ hours $(\mathrm{p}=0.002)$, and 24 hours $(\mathrm{p}=0.031)$ postoperatively.

\section{Aftercare}

Postoperatively, all patients were discharged to the PACU and their pain was managed by the anesthesiologists and trained nursing staff. Pain medication was administered based on the VAS and included nonnarcotic and narcotic pain medication. All cases were performed as ambulatory surgery and all patients were discharged home with a standardized postoperative analgesia prescription for oxycodone and acetaminophen $5 / 325 \mathrm{mg}$, one to two tablets to be taken as needed every 4 to 6 hours once their pain was adequately controlled.

Total time and medications administered in the PACU were documented. Patients were discharged home with a VAS questionnaire and were interviewed via telephone by a member of the research staff who was aware of the patient's study group, at 2 hours (from time of incision closure), 4, 6, 12, 24, 48, and 72 hours postoperatively, to gather VAS pain scores and to document the number of oral analgesics consumed (Fig. 1).

\section{Description of Followup Routine}

At the 2-week followup, the amount of analgesics consumed and VAS scores were recorded. Patients then were followed for a minimum of 12 weeks or until maximal clinical improvement was achieved. The minimal standard followup routine was to assess patients at 2, 6, and 12 weeks postoperatively. Functional outcome scores were assessed at 6 weeks and 12 weeks using the DASH and Short Musculoskeletal Function Assessment questionnaires. At 6-weeks, four patients (11.1\%) (two who received brachial plexus blockade, two who received general anesthesia) were lost to followup. At 12 weeks, an additional nine patients [25\%] (three who received brachial plexus blockade, six who received general anesthesia) were lost to followup.

Variables, Outcome Measures, Data Sources, and Bias

The operative surgeon was blind to the patient's randomization status at the time of surgery and at followup. The primary outcome evaluated was pain, as measured by the VAS. Data points were collected at 2, 4, 6, 12, 24, 48, and 72 hours, and 2 weeks after surgery. Data were collected in person when the patient was in-house and via telephone after discharge.

Secondary outcomes included time in the operative suite, time in the PACU, total pain medication used while in the PACU, total pain medication used during followup, and functional outcome scores. Time in the operative suite was determined via chart review and defined as the time elapsed from when the patient entered and exited the suite. Similarly, time in the PACU was determined via chart review and defined as the time elapsed between entering and exiting the unit. Pain medication used while in the PACU was determined via chart review and was recorded as the total dose per pain medication consumed while in the unit. Pain medication during the postoperative period was defined as the number of pain tablets taken after discharge from the PACU. This was determined via telephone interview at times coinciding with VAS data collection. The data were recorded as number of tablets taken per time and the total number of tablets taken during the postoperative period was determined for each subject; differences in mean total consumption were analyzed. We also calculated cumulative pain medication intake from postoperative to final followup using a standardized equianalgesic conversion table and compared the two groups [11].

Finally, functional assessment was analyzed using the DASH and Short Musculoskeletal Function Assessment questionnaires. These data were collected either in person or telephone interview.

\section{Statistical Analysis, Study Size}

A power analysis was performed and determined that with an assumed $20 \%$ dropout rate, the number of patients needed was 25 per group for a total of 50 patients to show a significant difference of three points on the VAS. Power analysis calculations were based on an $80 \%$ power to detect a three-point VAS scale difference with an alpha of 0.05 . However we had obtained statistically significant results per our primary outcome with only 36 patients enrolled and therefore discontinued enrollment. 
Table 2. Postoperative pain scores

\begin{tabular}{|c|c|c|c|c|}
\hline \multirow[t]{2}{*}{ Postoperative time } & \multicolumn{2}{|c|}{ VAS score (mean, [SD]) } & \multirow[t]{2}{*}{ Mean difference $(95 \% \mathrm{CI})$} & \multirow[t]{2}{*}{$\mathrm{p}$ value } \\
\hline & General anesthesia & Brachial plexus blockade & & \\
\hline 2 hours & $6.7[2.3]$ & $1.4[2.3]$ & $5.3(3.7-6.9)$ & $<0.001$ \\
\hline 4 hours & $5.6[2.7]$ & $4.1[3.3]$ & $1.6(-0.5$ to 3.6$)$ & 0.131 \\
\hline 6 hours & $4.4[2.5]$ & $6.2[2.6]$ & $-1.8(-3.7$ to 0.3$)$ & 0.054 \\
\hline 12 hours & $3.8[1.9]$ & $6.6[2.0]$ & $-2.9(-4.2$ to -1.5$)$ & $<0.001$ \\
\hline 24 hours & $3.8[2.2]$ & $5.5[2.4]$ & $-1.7(-3.3$ to -0.2$)$ & 0.032 \\
\hline 48 hours & 2.8 [1.5] & $2.9[1.8]$ & $-0.2(-1.3$ to 1.0$)$ & 0.767 \\
\hline 72 hours & $2.3[1.3]$ & $2.3[1.9]$ & $0.0(-1.1$ to 1.1$)$ & 1.00 \\
\hline 2 weeks & 1.7 [1.1] & $1.4[2.0]$ & $0.2(-0.9$ to 1.3$)$ & 0.713 \\
\hline
\end{tabular}

We used Student's t-test to compare differences in outcomes. Multiple linear regression analysis was used to evaluate the relationship between the groups and VAS pain while controlling for age, sex, and OTA classification. There were no patient dropouts after randomization, and analyses were performed according to an intention-to-treat model. All statistical analyses were performed with SPSS Version 20.0 (IBM Corp, Armonk, NY, USA), and statistical significance was set to a probability less than 0.05 .

\section{Results}

There were no readmissions for either group and no adverse events recorded. The general anesthesia group reported greater pain levels at 2 hours postoperatively (general anesthesia $6.7 \pm 2.3$ vs brachial plexus blockade $1.4 \pm 2.3$; mean difference, 5.381; 95\% CI, 3.850-6.913; $\mathrm{p}<0.001)$. This relationship was confirmed by the multiple regression analysis where patients in the general anesthesia group were associated with increased VAS pain levels ( $\beta$, 4.63; 95\% CI, 3.06-6.21). Pain scores for patients in the general anesthesia group then decreased during the 24-hour postoperative period. Meanwhile, mean pain for the brachial plexus blockade group trended upward postoperatively and was greater than that of the general anesthesia group at 12 hours (general anesthesia $3.8 \pm 1.9$ vs brachial plexus blockade $6.3 \pm 2.4$; mean difference, $-2.535 ; 95 \%$ $\mathrm{CI},-4.028$ to $-1.040 ; \mathrm{p}=0.002$ ) and 24 hours (general anesthesia $3.8 \pm 2.2$ vs brachial plexus blockade $5.3 \pm 2.5$; mean difference, $-1.492 ; 95 \% \mathrm{CI},-3.105$ to $0.120 ; \mathrm{p}=$ $0.031)$ postoperatively. The multivariate analysis confirmed this relationship (12 hours: $\beta,-2.86,95 \% \mathrm{CI}$, -4.21 to $-1.51 ; 24$ hours: $\beta,-1.70,95 \% \mathrm{CI},-3.24$ to -0.16). At 48 hours, mean pain scores were not different with the numbers available for patients who received brachial plexus blockade or general anesthesia and these scores then decreased in both groups in a linear fashion when plotted against followup times of 72 hours and 2 weeks (Table 2).

There was no difference in operative suite time (general anesthesia $119 \pm 16$ minutes vs brachial plexus blockade $125 \pm 23$ minutes; mean difference, 5.48 minutes; 95\% CI, -19.55 to $8.5 ; \mathrm{p}=0.433$ ), but time in the recovery room was greater for patients who received general anesthesia (general anesthesia $284 \pm 131$ minutes vs brachial plexus blockade $197 \pm 89$ minutes; mean difference, $87.2 ; 95 \%$ CI, $11.2-163.2 ; \mathrm{p}=0.026)$. Overall, there were no anesthesia-related complications recorded.

The general anesthesia group used more fentanyl while in the PACU (mean, $64 \mu \mathrm{g} \pm 93 \mu \mathrm{g}$ compared with $6.9 \mu \mathrm{g}$ $\pm 14 \mu \mathrm{g}$; mean difference, $57.1 \mu \mathrm{g}$; 95\% CI, 11.9-102.3; $\mathrm{p}<0.001)$.Mean morphine use for the general anesthesia group while in the PACU was $2.9 \mathrm{mg} \pm 3.6 \mathrm{mg}$ whereas mean morphine use in the brachial plexus blockade group was 0.0 (mean difference, $2.9 \mathrm{mg}$; 95\% CI, 1.1-4.6; $\mathrm{p}<$ 0.001). Postdischarge analgesic intake did not differ, the brachial plexus blockade group used a mean of 22.1 $( \pm 15.2)$ analgesic tablets whereas patients in the general anesthesia group used a mean $23.5( \pm 23.8)$ analgesic tablets (mean difference, 1.35 tablets; 95\% CI, -12.5 to $15.1 ; p=0.844)$. However, when analyzing the total opioid use by time, there was greater intake of oral analgesics by the brachial plexus blockade group at 12 hours postoperatively. Opioid use was greater in patients who received a brachial plexus blockade during the 6-hour interval (from 6 to 12 hours; mean tablets, $1.6 \pm 1.0$ versus $2.8 \pm 0.9$; mean difference, $1.1 ; 95 \% \mathrm{CI}, 0.5-1.8 ; \mathrm{p}=0.002)$ and cumulatively at 12 hours (mean tablets, $3.9 \pm 1.5$ versus $5.1 \pm 1.6$; mean difference, $1.17 ; 95 \% \mathrm{CI}, 0.1-2.2 ; \mathrm{p}=0.032$ ). The brachial plexus blockade group used less equivalents of pain medication compared with the general anesthesia group during the course of the study (5.1 compared with 10.5; mean difference, $5.4 ; 95 \% \mathrm{CI}, 2.2-8.5 ; \mathrm{p}=0.002$ ). 
Table 3. DASH and SMFA at 6 weeks and 12 weeks

\begin{tabular}{|c|c|c|c|c|}
\hline Scoring parameter & General anesthesia & Brachial plexus blockade/regional anesthesia & Mean difference $(95 \% \mathrm{CI})$ & $\mathrm{p}$ value \\
\hline DASH at 6-weeks (mean, [SD]) & $33.7[19.4]$ & $26.7[25.6]$ & $7.1(-10.2$ to 24.3$)$ & 0.408 \\
\hline \multicolumn{5}{|l|}{ SMFA at 6-weeks (mean, [SD]) } \\
\hline Function & 29.8 [20.7] & $29.3[29.1]$ & $0.5(-18.6$ to 19.7$)$ & 0.956 \\
\hline Bothersome & $18.3[17.0]$ & $19.1[23.2]$ & $-0.8(-16.2$ to 14.6$)$ & 0.915 \\
\hline Activity & $25.3[18.6]$ & $25.1[25.9]$ & $0.2(-16.9$ to 17.3$)$ & 0.982 \\
\hline Emotion & $22.2[16.9]$ & $20.7[18.0]$ & $1.5(-11.8$ to 14.8$)$ & 0.821 \\
\hline Arm \& hand & $29.1[21.9]$ & $29.7[32.0]$ & $-0.6(-21.3$ to 20.2$)$ & 0.955 \\
\hline Mobility & $4.7[8.8]$ & $6.2[20.7]$ & $-1.5(-13.5$ to 10.4$)$ & 0.793 \\
\hline DASH at 12 -weeks (mean, [SD]) & $17[17.5]$ & $11.6[11]$ & $5.4(-7.1$ to 18$)$ & 0.377 \\
\hline \multicolumn{5}{|l|}{ SMFA at 12 -weeks (mean, $[\mathrm{SD}])$} \\
\hline Function & $18.8[16.1]$ & $14.1[12.8]$ & $4.7(-8.2$ to 17.7$)$ & 0.455 \\
\hline Bothersome & $13.6[23.6]$ & 7.0 [7.9] & $6.6(-9.1$ to 22.3$)$ & 0.388 \\
\hline Activity & $13.0[16.1]$ & $7.7[10.3]$ & $5.3(-6.8$ to 17.3$)$ & 0.372 \\
\hline Emotion & $14.6[17.1]$ & $10.4[11.7]$ & $4.3(-8.8$ to 17.3$)$ & 0.503 \\
\hline Arm \& hand & $16.7[17.5]$ & $10.8[12.4]$ & $5.9(-7.6$ to 19.4$)$ & 0.371 \\
\hline Mobility & $3.1[7.5]$ & $2[5.7]$ & $1.1(-4.8$ to 7$)$ & 0.706 \\
\hline
\end{tabular}

SMFA $=$ Short Musculoskeletal Function Assessment

Functional outcome scores with the Short Musculoskeletal Function Assessment and DASH showed no difference at 6 weeks and 12 weeks (Table 3).

\section{Discussion}

Regional anesthesia has a proven track record for safety and quality pain control in extremity surgery, and is currently considered a standard of care, as is general anesthesia. A recent study has shed light on the phenomena of rebound pain associated with the resolution of regional anesthesia in the extremity [10]. Currently, surgeons do not know how best to counsel patients on the benefits of regional anesthesia versus general anesthesia for distal radius fracture fixation as the effects of rebound pain and immediate postoperative pain are not well documented for this surgical treatment [8]. Postoperative pain after orthopaedic surgery has been shown to be associated with greater than pain with other types of surgery, and because of this, research has been done to improve the patient's postoperative experience [6]. The use of regional anesthesia is well established, but for surgery distal to the elbow no data are available to compare the efficacy of a peripheral nerve block with general anesthesia. The purpose of our prospective randomized study was to compare brachial plexus blockade and general anesthesia for postoperative pain control after open reduction and internal fixation of distal radius fractures. To the best of our knowledge, this is the first randomized trial comparing these modalities after operative fixation of distal radius fractures.

This study has some limitations including the lack of some data at every time (owing to difficulty with obtaining telephone followups with patients at various times), although we had $89 \%$ or better data followup rates at each postoperative assessment of pain and narcotic use. Another limitation of our study was the challenge of blinding the surgeon, anesthesiologist, or patient. Although this would tend to favor the brachial plexus block arm of our study, this did not occur in our study. The study also was limited in that there was no standardization of postoperative adjuvant pain medications, the management of which ultimately was dictated by collaborative efforts between nursing staff in the PACU and the patient's subjective reports. This however proved inconsequential as patients in the general anesthesia group still had more pain immediately postoperatively as expected.

General anesthesia is associated with greater immediate postoperative pain, whereas brachial plexus blockade is associated with delayed rebound pain. We found that while initial pain control in the PACU (measured 2 hours postoperatively) was better with a brachial plexus blockade, this group experienced a nonlinear increase in pain during the perioperative period which was greatest at 12 to 24 hours postoperatively. In contrast to the findings of patients who received general anesthesia, patients who received a brachial plexus blockade which when coupled with increased fentanyl or morphine use in the PACU (increased use compared with the brachial plexus blockade group), 
these patients were provided with a steady linear downward trend in postoperative pain. This is consistent with other studies comparing single-injection nerve blocks and general anesthesia for other orthopaedic surgeries [10, 23]. This finding is important for the understanding, management, and counseling of patients regarding perioperative pain expectations and control. Patients should be counseled to anticipate pain 12 to 24 hours after their regional anesthesia wears off that may be severe if not modulated with oral analgesics before the onset of the pain. The reason for reversal in pain levels may be related to the phenomenon of "rebound pain," a poorly described entity that is commonly defined as a dramatic increase in pain once singleinjection regional anesthesia has dissipated [18, 20]. Different regions of the body have been shown to experience rebound pain after regional anesthesia at different times, modulated by increasing the length of analgesic efficacy [23]. In a retrospective study of patients receiving a femoral nerve block with a perineural catheter for ACL reconstruction, rebound pain was a common phenomenon as seen by increases in VAS scores once the analgesic stopped working, but was attenuated by longer-duration analgesia at a minimum of 33 hours [23]. In a prospective study of patients undergoing shoulder arthroscopy, rebound pain occurred 1 to 2 days postoperatively after interscalene block [20]. Goldstein et al. [10], described a similar phenomenon related to ankle fracture fixation and popliteal blocks with an acute increase in pain at approximately 24 hours postoperatively.

In our study, although operative time did not differ statistically (overall a mean of 5.5 additional minutes for the regional anesthesia group), the general anesthesia group had significantly longer PACU times and used significantly more pain medication in the PACU and cumulatively, a finding which is consistent with some previous studies [13, 24]. Once pain was under control and patients were comfortable, they were discharged home and able to regulate their pain with oral analgesics. The brachial plexus blockade group left the PACU earlier because they were comfortable during the immediate postoperative period $[7,23]$.

The general anesthesia group used more narcotics while in the PACU, but total postdischarge narcotic use did not differ significantly between the two groups. Even though overall narcotic consumption was not different, because of rebound pain in the brachial plexus blockade group shortly after surgery, these patients might need to be educated on the importance of taking their oral analgesics before the onset of pain. Echoing the findings and conclusions of Goldstein et al. [10] for counseling patient's postoperatively after regional anesthesia for ankle fractures, we believe that patients receiving a brachial plexus blockade can minimize their pain during the 12- to 24-hour postoperative period by preemptively taking oral pain medications 1 to 2 hours before the regional anesthesia begins to wane. This requires thorough counseling of patients and their family members during the 2 to 3 hours immediately after surgery. We believe patients with regional anesthesia in our study waited for the first onset of pain and did not aggressively take postoperative pain medication before the block wore off. Patients who do not take adequate analgesics before the onset of rebound pain may have difficulty gaining control over their pain once it has set in, however we believe this can be mitigated by judicious use of oral narcotics before this. In this study, with the $.25 \%$ bupivacaine diluted with $2 \%$ lidocaine, the strongest rebound in pain was seen after brachial plexus blockade at 12 hours postoperative.

Functional outcome scores did not differ between the two groups, which is in contrast to a previous retrospective study that showed patients receiving brachial plexus blockade had improved outcomes, in particular, at 6 to 12 weeks followup [8]. More research needs to be performed to elucidate these relationships in addition to longer followup focusing on functional outcomes.

Although regional anesthesia provides early short-term pain relief, patients have greater pain once they are discharged from the hospital and their regional blocks dissipate. Although treatment with regional analgesia can be effective, we recommend a thorough discussion with patients, making them aware of the rebound pain phenomenon after regional anesthesia and counseling them on safe, but aggressive (that is, before the onset of pain), use of postoperative oral analgesics in the setting of regional anesthesia. Use of regional blocks also may allow for earlier discharge, but the importance of early bridging with preemptive oral narcotics cannot be overemphasized with nursing staff, the patients, and family members to avoid postdischarge pain and perioperative morbidity and modifiable discomfort. Future research will focus on ways to modulate rebound pain postoperatively to allow a seamless transition from regional anesthesia to oral analgesics. These can include long-acting local anesthetics or indwelling pain pumps which patients may have even when discharged to home.

Acknowledgments We thank Raj Karia MPH (NYU Hospital for Joint Diseases, New York, NY, USA) for his contributions and assistance with statistical analysis.

\section{References}

1. Arora R, Gabl M, Gschwentner M, Deml C, Krappinger D, Lutz M. A comparative study of clinical and radiologic outcomes of unstable Colles type distal radius fractures in patients older than 70 years: nonoperative treatment versus volar locking plating. $J$ Orthop Trauma. 2009;23:237-242. 
2. Arora R, Lutz M, Deml C, Krappinger D, Haug L, Gabl M. A prospective randomized trial comparing nonoperative treatment with volar locking plate fixation for displaced and unstable distal radial fractures in patients sixty-five years of age and older. $J$ Bone Joint Surg Am. 2011;93:2146-2153.

3. Brown AR, Weiss R, Greenberg C, Flatow EL, Bigliani LU. Interscalene block for shoulder arthroscopy: comparison with general anesthesia. Arthroscopy. 1993;9:295-300.

4. Bruce BG, Green A, Blaine TA, Wesner LV. Brachial plexus blocks for upper extremity orthopaedic surgery. J Am Acad Orthop Surg. 2012;20:38-47.

5. Chelly JE, Greger J, Al Samsam T,Gebhard R, Masson M, Matuszczak M, Sciard D. Reduction of operating and recovery room times and overnight hospital stays with interscalene blocks as sole anesthetic technique for rotator cuff surgery. Minerva Anestesiol. 2001;67:613-619.

6. Chung KC, Pushman AG. Current concepts in the management of the rheumatoid hand. J Hand Surg Am. 2011;36:736-747; quiz 747.

7. DeMarco JR, Componovo R, Barfield WR, Liles L, Nietert P. Efficacy of augmenting a subacromial continuous-infusion pump with a preoperative interscalene block in outpatient arthroscopic shoulder surgery: a prospective, randomized, blinded, and placebo-controlled study. Arthroscopy. 2011;27:603-610.

8. Egol KA, Soojian MG, Walsh M, Katz J, Rosenberg AD, Paksima N. Regional anesthesia improves outcome after distal radius fracture fixation over general anesthesia. J Orthop Trauma. 2012;26:545-549.

9. Egol K, Walsh M, Tejwani N, McLaurin T, Wynn C, Paksima N. Bridging external fixation and supplementary Kirschner-wire fixation versus volar locked plating for unstable fractures of the distal radius: a randomised, prospective trial. J Bone Joint Surg Br. 2008;90:1214-1221.

10. Goldstein RY, Montero N, Jain SK, Egol KA, Tejwani NC. Efficacy of popliteal block in postoperative pain control after ankle fracture fixation: a prospective randomized study. J Orthop Trauma. 2012;26:557-561.

11. Gordon DB, Stevenson KK, Griffie J, Muchka S, Rapp C, FordRoberts K. Opioid equianalgesic calculations. J Palliat Med. 1999;2:209-218.

12. Grewal R, MacDermid JC, Faber KJ, Drosdowech DS, King GJ. Comminuted radial head fractures treated with a modular metallic radial head arthroplasty: study of outcomes. J Bone Joint Surg Am. 2006;88:2192-2200.

13. Hadzic A, Williams BA, Karaca PE, Hobieka P, Unis G, Dermksian J, Yufa M, Thys DM, Santos AC. For outpatient rotator cuff surgery, nerve block anesthesia provides superior same-day recovery over general anesthesia. Anesthesiology. 2005;102:1001-1007.

14. Halaszynski TM. Ultrasound brachial plexus anesthesia and analgesia for upper extremity surgery: essentials of our current understanding, 2011. Curr Opin Anaesthesiol. 2011;24:581-591.

15. Lee HY, Kim SH, So KY, Kim DJ. Effects of interscalene brachial plexus block to intra-operative hemodynamics and postoperative pain for arthroscopic shoulder surgery. Korean $J$ Anesthesiol. 2012;62:30-34.

16. Mariano ER, Sandhu NS, Loland VJ, Bishop ML, Madison SJ, Abrams RA, Meunier MJ, Ferguson EJ, Ilfeld BM. A randomized comparison of infraclavicular and supraclavicular continuous peripheral nerve blocks for postoperative analgesia. Reg Anesth Pain Med. 2011;36:26-31.

17. Mirza F, Brown AR. Ultrasound-guided regional anesthesia for procedures of the upper extremity. Anesthesiol Res Pract. 2011;2011:579824. doi:10.1155/2011/579824.

18. Mulroy M, Larkin KL, Batra MS, Hodgson PS, Owens BD. Femoral nerve block with $0.25 \%$ or $0.5 \%$ bupivacaine improves postoperative analgesia following outpatient arthroscopic anterior cruciate ligament repair. Reg Anesth Pain Med. 2001;26:24-29.

19. Schroeder LE, Horlocker TT, Schroeder DR. The efficacy of axillary block for surgical procedures about the elbow. Anesth Analg. 1996;83:747-751.

20. Stiglitz Y, Gosselin O, Sedaghatian J, Sirveaux F, Mole D. Pain after shoulder arthroscopy: a prospective study on 231 cases. Orthop Traumatol Surg Res. 2011;97:260-266.

21. Strode JE. Brachial plexus block anesthesia: its advantages in the treatment of fractures of the arm: report of cases. Cal West Med. 1929;31:17-20.

22. Tetzlaff JE, Yoon HJ, Brems J. Patient acceptance of interscalene block for shoulder surgery. Reg Anesth. 1993;18:30-33.

23. Williams BA, Bottegal MT, Kentor ML, Irrgang JJ, Williams JP. Rebound pain scores as a function of femoral nerve block duration after anterior cruciate ligament reconstruction: retrospective analysis of a prospective, randomized clinical trial. Reg Anesth Pain Med. 2007;32:186-192.

24. Wu CL, Rouse LM, Chen JM, Miller RJ. Comparison of postoperative pain in patients receiving interscalene block or general anesthesia for shoulder surgery. Orthopedics. 2002;25:45-48. 